\title{
A LONGITUDINAL STUDY OF MONITORING ADVERSE DRUG REACTIONS AT PSYCHIATRY OUT-PATIENT-DEPARTMENT IN OUR TERTIARY CARE TEACHING HOSPITAL, SURENDRANAGAR
}

\author{
*Shah VM ${ }^{1}$, Mehta DS ${ }^{2}$ \\ ${ }^{1}$ P.G. student, Department of pharmacology, C.U.S.M.C., Surendranagar, Gujarat, India \\ ${ }^{2}$ Professor \& Head, Department of pharmacology, C.U.S.M.C., Surendranagar, Gujarat, India \\ *Corresponding Author's E-mail:Vidisha_pharmac@yahoo.com
}

\begin{abstract}
Objectives: Adverse Drug Reactions (ADRs) are common to the psychotropic drugs in our teaching hospital and here, we study to determine suspected ADRs in psychiatry O.P.D. Materials and Methods: In order to evaluate the incidence of ADRs in psychiatry O.P.D., we performed a longitudinal observational study between May 2012 and July 2012. All the patients were interviewed for basic details, history of medications and for the relevant history for ADRs. All details were captured in a format as adopted in the Indian National Pharmacovigilance Programme. Causality was assessed by criteria of World Health Organization-Uppsala Monitoring Center (WHO-UPC). Result: We observed 4169 patients (males 64.28\%, females $35.71 \%$, median age 40 years), of who 28 were diagnosed as having at least one ADR; Cases who had insufficient evidence about causality (WHO-UMC causality status "unlikely") were excluded from further analysis. Out of 28 events recorded, 12 (42.85\%) were "probable" and 12(42.85\%) were "possible". Rest of them was labeled as "certain". Total of 43 ADRs were noted in 28 patients. Maximum number of ADR noted was nausea which was followed by weight gain. Highest number of ADRs was reported with Amitriptyline and Duloxetine.
\end{abstract}

Key Words: Adverse Drug Reactions (ADRs), Psychiatry O.P.D., Psychotropic drugs.

\section{INTRODUCTION:}

Adverse drug reactions (ADRs) are as important in psychiatric practice as they are in any other branch of medicine. The safety of medicines is an essential part of patient safety. Global drug safety depends on strong national systems that monitor the development and quality of medicines, report their harmful effects, and provide accurate information for their safe use. ADRs are defined as an 'unexpected, unintended, undesired or excessive response to a drug', which would include 'allergic reactions and idiosyncratic reactions that are an abnormal susceptibility to a drug peculiar to the individual'. ${ }^{1}$ All noxious and unintended responses to a medicinal product related to any dose should be considered adverse drug reaction. ${ }^{2}$ ADRs only affect a minority of those taking a particular drug. It is often seen that commonly prescribed drugs, elicit ADR in some, at the same time many remain unaffected. Pharmacovigilance is, "The Pharmacological Science relating to the detection, assessment, understanding and prevention of adverse effects, particularly long term and short term side effects of medicines." ${ }^{3}$ Pharmacovigilance in psychiatry units can play a vital role in detecting ADRs and alerting physicians to the possibility and circumstances of such events, thereby protecting the user population from avoidable harm. ${ }^{4}$ Many psychotropic drugs are available in India and their use is increasing day by day. Commonly used psychotropic drugs in psychiatry O.P.D. are the drugs used for psychoses, depression, epilepsy, mania, migraine and insomnia. These drugs are capable of causing a number of ADRs, ${ }^{5,6}$ some of which may be fatal. Most commonly ADRs are seen with antipsychotics and mood stabilizers. ADRs associated with psychotropic drugs can lead to noncompliance, and at times discontinuation of therapy. ${ }^{7}$ In India, pharmacovigilance activities are still in the nascent stage and the data of ADRs particularly related to psychotropic drugs need to be strengthened. ${ }^{8}$

\section{Objectives:}

To determine the incidence of ADRs and to assess the causality of ADRs in psychiatry O.P.D. at our tertiary care teaching hospital.

\section{MATERIALS AND METHODS:}

A longitudinal observational study was carried out at our psychiatry out-patient-department (OPD) in a tertiary care teaching hospital. This hospital caters to the health care needs of thousands of patients from Surendranagar city, many villages and town around the city. It was part of ongoing pharmacovigilance activity at the Institute which had the necessary administrative and Institutional Ethics Committee (IEC) clearance.

The data was collected prospectively of the patients reporting to psychiatry OPD. The study was carried out for 3 months between May 2012 and July 2012. Out of 4169 patients attending to psychiatry OPD within these 3 months, the patients with ADRs were evaluated. Diagnosis of ADR was made by psychiatrist. All the doctors, residents, interns, and nursing staff were informed to notify any suspected ADRs. Patient details (age, sex, body weight), adverse event history, history of medication suspected of having caused the ADR, and details of concomitant medication use were recorded in 
the format followed in the Indian National Pharmacovigilance Programme. ${ }^{9}$ Causality of the event was assessed by World Health Organization-Uppsala
Monitoring Centre (WHO-UMC) criteria. $^{10]}$ Suspected ADRs with causality status less than "possible" were excluded from the study.

\section{RESULTS:}

A total of 4169 patients observed for the study, out of which $28(0.67 \%)$ were diagnosed as having at least one ADR, diagnosed by psychiatrist. A total of 43 ADRs were noted from 15 psychotropic drugs.

Table 1: Age \& Sex wise distribution of ADRs

\begin{tabular}{|l|l|l|l|l|}
\hline Sr. No. & Age Group ( in years) & No. of Male patients & No. of Female patients & Total no. of patients \\
\hline 1. & $<25$ & 3 & 0 & 3 \\
\hline 2. & $25-40$ & 9 & 4 & 13 \\
\hline 3. & $40-55$ & 2 & 5 & 7 \\
\hline 4. & $>55$ & 4 & 1 & 5 \\
\hline & Total & 18 & 10 & 28 \\
\hline
\end{tabular}

Table 1 shows that most common age group is $25-40$ years (46.42\%) with female preponderance only in age group 40 55 years. In other age groups, male preponderance is seen. Median age was 40 years. It also shows that total no. of males $(64.28 \%)$ are having more ADRs than female $(35.71 \%)$.

Table 2: Various types of ADRs and no. of them

\begin{tabular}{|l|l|l|}
\hline Type of ADRs & Drugs causing ADRs & $\begin{array}{l}\text { No. of } \\
\text { ADRs }\end{array}$ \\
\hline Hypersomnia & Gabapentin, Clozapine, Venlafexine, Alprazolam & 4 \\
\hline Dizziness & Gabapentin, Alprazolam & 2 \\
\hline Headache & Ethosuximide, Duloxetine, Escitalopram, Alprazolam & 4 \\
\hline Drowsiness & Ethosuximide, Escitalopram, Alprazolam & 3 \\
\hline Skin Rashes & Phenytoin(2), Carbamazepine, Clozapine & 4 \\
\hline Gingivial swelling & Phenytoin & 1 \\
\hline Weight gain & Valproate, Olanzapine, Amitriptyline(2), Olanzapine & 5 \\
\hline Nausea & Valproate, Carbamazepine, Venlafexine, Duloxetine(3) Escitalopram(2), Lithium & 9 \\
\hline Vomiting & Carbamazepine, Sertaline, Duloxetine & 3 \\
\hline Diarrhea & Sertaline(2) & 2 \\
\hline Jaundice & Haloperidol & 1 \\
\hline Seizures & Amitriptyline & 1 \\
\hline Insomnia & Duloxetine & 1 \\
\hline $\begin{array}{l}\text { Decrease frequency of } \\
\text { micturition }\end{array}$ & Amitriptyline & 1 \\
\hline Tremors & & 2 \\
\hline
\end{tabular}

Table 2 displays that maximum number of ADRs seen is nausea, which is 9(20.93\%) in number and is followed by weight gain (11.63\%). Severe ADR like seizure is seen only in 1(2.32\%) case which was due to Amitriptyline.

Table 3: Various groups of drugs causing ADRs

\begin{tabular}{|l|l|l|}
\hline Group of drugs & Name of drugs & No. of ADRs observed \\
\hline Anti-epileptic drugs & Phenytoin, Ethosuximide, Carbamazepine, Valproate, Gabapentin & 12 \\
\hline Anti-psychotic drugs & Clozapine, Olanzapine, Haloperidol & 6 \\
\hline Anti-depressant drugs & Duloxetine, Escitalopram, Amitripyline, Sertaline, Venlafexine & 18 \\
\hline Anti-manic drugs & Lithium & 2 \\
\hline Sedative \& Hypnotics & Alprazolam & 4 \\
\hline Drugs for Migraine & Amitriptyline & 1 \\
\hline
\end{tabular}

Table 3 shows that most common group of drug causing ADRs is Anti-depressant drugs (41.86\%) followed by antiepileptic drugs $(27.90 \%)$. And least common is with drugs for migraine (2.43\%). 
Table 4: Various ADRs on Causality assessment scale

\begin{tabular}{|l|l|l|l|}
\hline Sr. No. & Causality assessment & No. of patients & Percent \\
\hline 1. & Certain & 4 & 14.28 \\
\hline 2. & Probable & 12 & 42.85 \\
\hline 3. & Possible & 12 & 42.85 \\
\hline
\end{tabular}

Table 4 displays that there is an equal number of patients for probable and possible analysis observed. 4 cases of Phenytoin, Escitalopram, Duloxetine and Alprazolam were rechallanged and ADR reappeared so they were included in certain criteria of WHO scale. Cases who had insufficient evidence about causality (WHO-UMC causality status "unlikely" or less than that) were excluded from further analysis.

\section{DISCUSSION:}

Present study has been done to report the incidence of ADRs to psychotropic drugs in the psychiatry OPD setting in the tertiary care hospital. A knowledge, practice and attitude based study conducted in Norway found that ADRs can be prevented by collecting reliable information about their frequencies and possible risk factors. ${ }^{[1]}$ Among all the ADRs reported, maximum number of ADRs are seen with antidepressant drugs. G.I. symptoms, headache and sexual effects are most common side effects seen with SSRIs and SNRI. ${ }^{[12]}$ Newer generation Escitalopram and Duloxetine are most commonly prescribed antidepressant drugs in our hospital. In our study, Duloxetine is the most common drug causing ADR. Sengupta et al., in their study ${ }^{[8]}$ - find that Olanzapine is the most common drug causing ADRs. ${ }^{8}$

The other common groups of drugs causing ADRs in our study are anti-epileptic drugs and antipsychotic drugs. Sengupta et al., in their study ${ }^{8}$ - find that anti-psychotic drugs are the most common group of drugs causing ADRs. Common side-effects with antiepileptic drugs that affect people include unsteadiness and sleepiness. Side-effects often happen when you start taking a new anti-epileptic drug, or if the dose is too high. ${ }^{13}$ In our study, Phenytoin and Carbamazepine are causing maximum side effects. Conventional or "typical" antipsychotics (e.g., Haloperidol etc.) were prescribed with associated limitations of poor efficacy against negative symptoms and unwanted Extra Pyramidal Symptoms (EPS), particularly at higher doses. ${ }^{14,15,16}$ In our study, haloperidol is causing tremors and jaundice. Over the last few years, atypical antipsychotics (e.g.,Clozapine, Olanzapine etc.) have been increasingly used in the pharmacological treatment of schizophrenia and other related psychotic disorders. Atypical antipsychotics differ from conventional agents in that they have lower risk of EPS and significantly reduce both positive and negative symptoms of schizophrenia. ${ }^{18}$ In our study, Olanzapine is causing weight gain and no any other ADRs.

In our study, most common ADR found was nausea followed by weight gain. Drug induced seizures, tremors and decreased frequency of micturition were rare findings.

\section{Weight gain:}

Weight gain is associated with the use of many psychotropic medications, including antidepressants, mood stabilizers, antipsychotic drugs, and may have serious long term consequences. ${ }^{17}$ Tricyclic Antidepressants (TCA) induced weight gain correlated positively with dosage and duration of treatment, more pronounced with Amitriptyline; Selective Serotonin Reuptake Inhibitors (SSRIs) decrease transiently body weight during the first few weeks of treatment and may then increase body weight; weight gain appears to be most prominent with some mood stabilizers (Lithium,Valproate); atypical antipsychotics tend to cause more weight gain than conventional one, seems to be more severe with Clozapine and Olanzapine. ${ }^{18}$ This supports our study as in our study, weight gain is produced by Amitriptyline, Valproate and Olanzapine.

\section{Drug induced tremors:}

A drug-induced tremor is involuntary shaking due to the use of medication. Drugs that can cause tremors are mood stabilizer (Lithium), anti-convulsant (Valproate) and others. Tremors are mostly relieved after stopping the drug. In rare cases, a drug such as Propanalol or Primidone may be added to help control the tremor. Here, in our study tremors are produced by Lithium (Anti-manic drug) and Haloperidol (Typicalantipsychotic drugs).

\section{Drug induced seizures:}

Seizure threshold is lowered with antidepressant drugs, so fits may be precipitated, especially in children. TCAs have greater propensity while SSRI and SNRI are safe in this regard. In our study, Amitriptyline, a tricyclic anti-depressant is causing drug induced seizures in a twenty three year old boy.

\section{Decrease frequency of micturition:}

Anti-depressant drugs are having anticholinergic effect. Anticholinergic effects appear most frequently and cause the greatest morbidity in geriatric patients. It causes urinary retention, especially in elderly male patient with enlarged prostate. In our study one case of urinary retention was noted with Amitriptyline.

\section{CONCLUSION}

This study gives a representative profile of ADRs to be expected in psychiatry out-patient in an Indian Tertiary care teaching hospital. Establishment of a psychotropic drug ADR database can be a worthy longterm goal in the Indian context. 


\section{REFERENCE:}

1. Common adverse drug reactions with psychiatric medications and an approach to their management; 2011. [cited on august, 2012] Available on

http://www.ajol.info/index.php/cme/article/viewFile/71989/60941.

2. ICH-GCP guidelines; 2011. [cited on august, 2012] Available on http://www.ich.org.

3. Tripathi KD.Adverse drug effects. Essentials of Medical Pharmacology, $6^{\text {th }}$ ed. New Delhi:Jaypee Brothers;2008:78-87.

4. Faich GA. US adverse drug reaction surveillance 1984-1994. Pharmacoepidemiol Drug Saf 1996; 5:393-8.

5. Arason JK. Risk perception in drug therapy. Br J Clin Pharmacol 2006;62:135-7.

6. Rani FA, Byrne PJ, Murray ML, Carter P, Wong IC. Paediatric atypical antipsychotic monitoring safety (PAMS) study: Pilot study in children and adolescents in secondary- and tertiarycare settings. Drug Saf 2009; 32:325-33

7. Cooper C, Bebbington P, King M, Brugha T, Meltzer H, Bhugra $\mathrm{D}$, et al. Why people don't take their psychotropic drugs as prescribed: Results of the 2000 National Psychiatric Morbidity Survey. Acta Psychiatr Scand 2007;116:47-53.

8. Sengupta G, Bhowmick S, Hazra A, Datta A, Rahaman M. Adverse drug reaction monitoring in psychiatry out-patient department of an Indian teaching hospital. Indian J Pharmacol 2011:43:36-9

9. Bavdekar SB, Karande S. National pharmacovigilance program. Indian Pediatr 2006; 43:27-32

10. The use of the WHO-UMC system for standardized case causality assessment [monograph on the Internet]. Uppsala: The Uppsala Monitoring Centre; 2005. [Cited on august, 2012] Available from: http://www.who-umc.org/graphics/4409.pdf.
11. Castberg I, Reimers A, Sandvik P, Amo TO, Spiqset O. Adverse drug reactions of antidepressant and antipsychotics.Experience, knowledge and attitudes among Norwegian psychiatrists. Nord J Psychiatry.2006; 60:227-33.

12. O'Donnell JM, Shelton RC. Drug therapy of Depression and Anxiety Disorders. Goodman \& Gilman's The Pharmacological Basis of Therapeutics, $12^{\text {th }}$ ed. San diego, calif: The McGraw-Hill Companies;2011:400-3.

13. Anti-epileptic drugs [cited on August,2010]. Available at http://www.epilepsy.org.uk/info/developing-epilepsy-laterlife/side-effects

14. Serretti A, De RD, Lorenzi C, Beradi D. New antipsychotics and schizophrenia: A review on efficacy and side effects. Curr Med Chem 2004; 11:343-58.

15. Liblin H, Eberhard J, Levander S. Current therapy issues and unmet clinical needs in the treatment of schizophrenia: A review of the new generation antipsychotics. Int Clin Psyhcopharamcol 2005; 20:183-98.

16. Gardner DM, Baldessarini RJ, Waraich P. Modern antipsychotic drugs: A critical overview. CMAJ 2005; 172: 1703-11

17. Piparva KG, Buch JG, Chandrani KV. Analysis of adverse drug reactions of atypical antipsychotic drugs in psychiatry OPD. Indian J Psychological medicine 2011:33:153-7.

18. Psychotropic drugs induced weight gain: a review of the literature concerning epidemiological data, mechanisms and management; 2005. [Cited in august, 2012]. Available at http://www.biopsychiatry.com/weight-gain.htm 